\title{
With or without you? Why the European Union's climate targets will be harder to meet post-Brexit
}

ISF blogs.Ise.ac.uk/brexit/2017/01/16/with-or-without-you-why-the-european-unions-climate-targets-will-be-harderto-meet-post-brexit/

The UK has played an important role in shaping and advancing European action on climate change. Without it, other Member States will find themselves picking up the slack or the EU will miss its greenhouse gas target for 2030, write Maria Carvalho and Sam Fankhauser.

The UK has some of the most ambitious greenhouse gas (GHG) reduction targets in the EU, and is reducing its emissions by much more than the EU target of $20 \%$ reduction from 1990 levels in by 2020 , and $40 \%$ by 2030 . The UK's Climate Change Act, the world's first act of its sort, set a legally binding target for the UK to reduce its GHG emissions by $80 \%$ on 1990 levels by 2050 . In June 2016 the government passed the fifth carbon budget to keep the UK on a cost-effective path to meet the 2050 target. The budget commits the UK to reduce its GHG emissions by $36 \%$ in 2020 and by $57 \%$ in 2030 .

The UK is not the only Member State to adopt ambitious 2030 reduction targets that go beyond the EU average. Others include Germany and Denmark, each with national reduction targets of $40 \%$ on 1990 levels by 2020 , and in the case of Germany, $95 \%$ reductions by 2050. Denmark also plans on making its energy and transport sector run on $100 \%$ renewables by 2050 . Nevertheless, the exit of the UK, one of Europe's climate

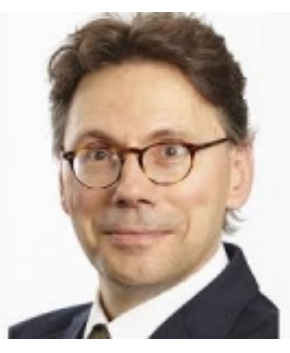
leaders, will have implications for the EU's efforts to meet its emissions reduction target of $40 \%$ on 1990 levels by 2030 .

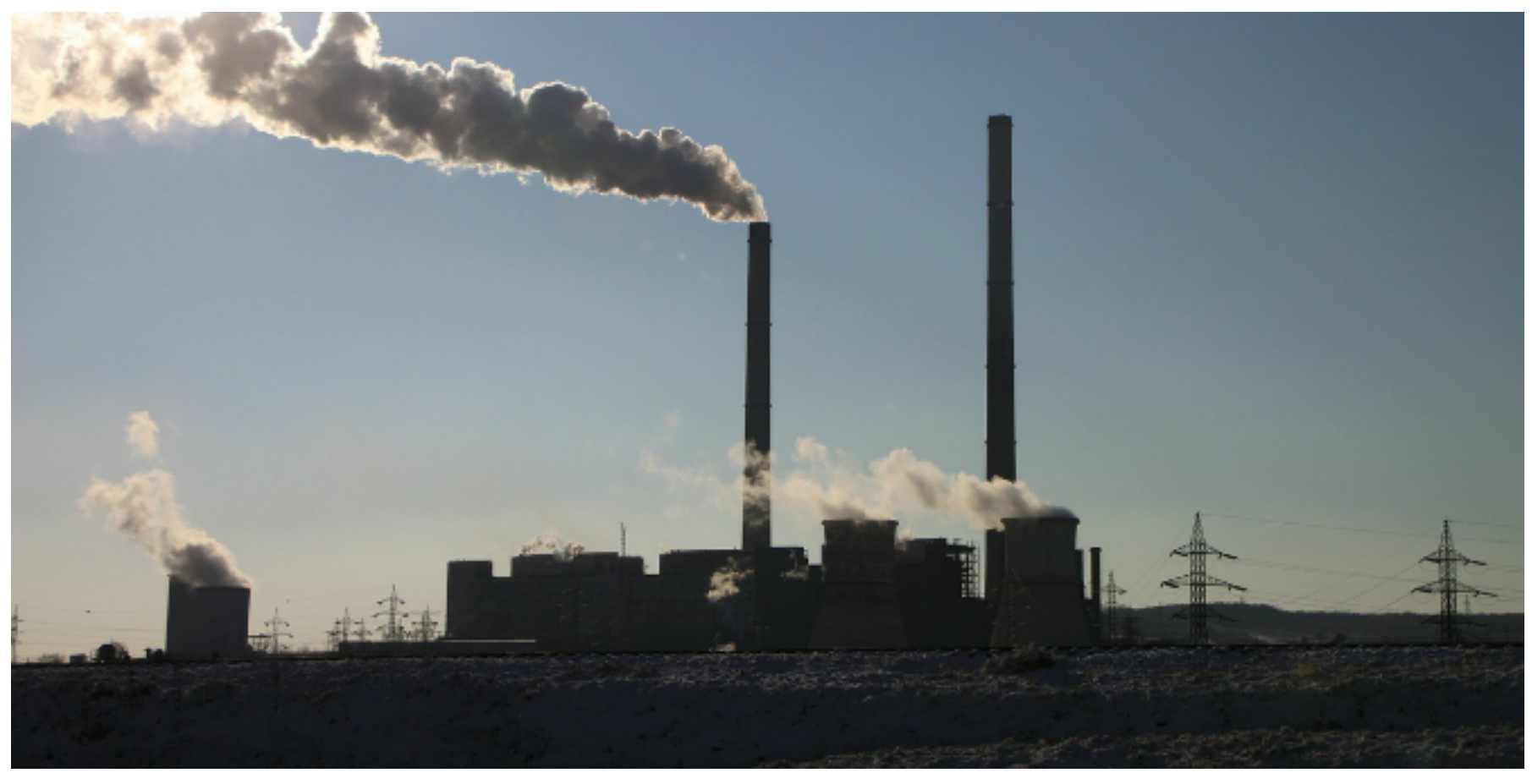

\section{The EU's carbon targets without the UK}

Figure 1 below compares the level of emissions the EU28 (with the UK) and the EU27 (without the UK) produced in the past and are allowed to emit in the future under the EU's GHG reduction targets. 
Brexit is unlikely to make much difference to the 2020 target. The latest emission figures (for 2014) show that while the UK is on track to meet the UK's own 2020 target, the EU has already met its 2020 targets- either with or without the UK. Moreover, the UK is not expected to leave the union until 2019.

However, the picture is very different for 2030. The exclusion of the UK from the EU's 2030 target means that the EU27 would need to increase its GHG reduction efforts by an additional 4.5\%, representing about $138 \mathrm{MtCO} 2 \mathrm{e}$. This figure is the combined equivalent of Austria and Ireland's emissions in 2014. The European Commission will be required to re-distribute these additional reductions amongst the remaining 27 Member States.

Softening the target is not an option. The Paris Agreement is built around the explicit expectation that national contributions will be ratcheted up over time and the credibility of the EU would be seriously harmed if it tried to adjust its targets down as a result of Brexit.

\section{Figure 1. Past \& future scenarios of meeting carbon reduction targets with and without the UK}

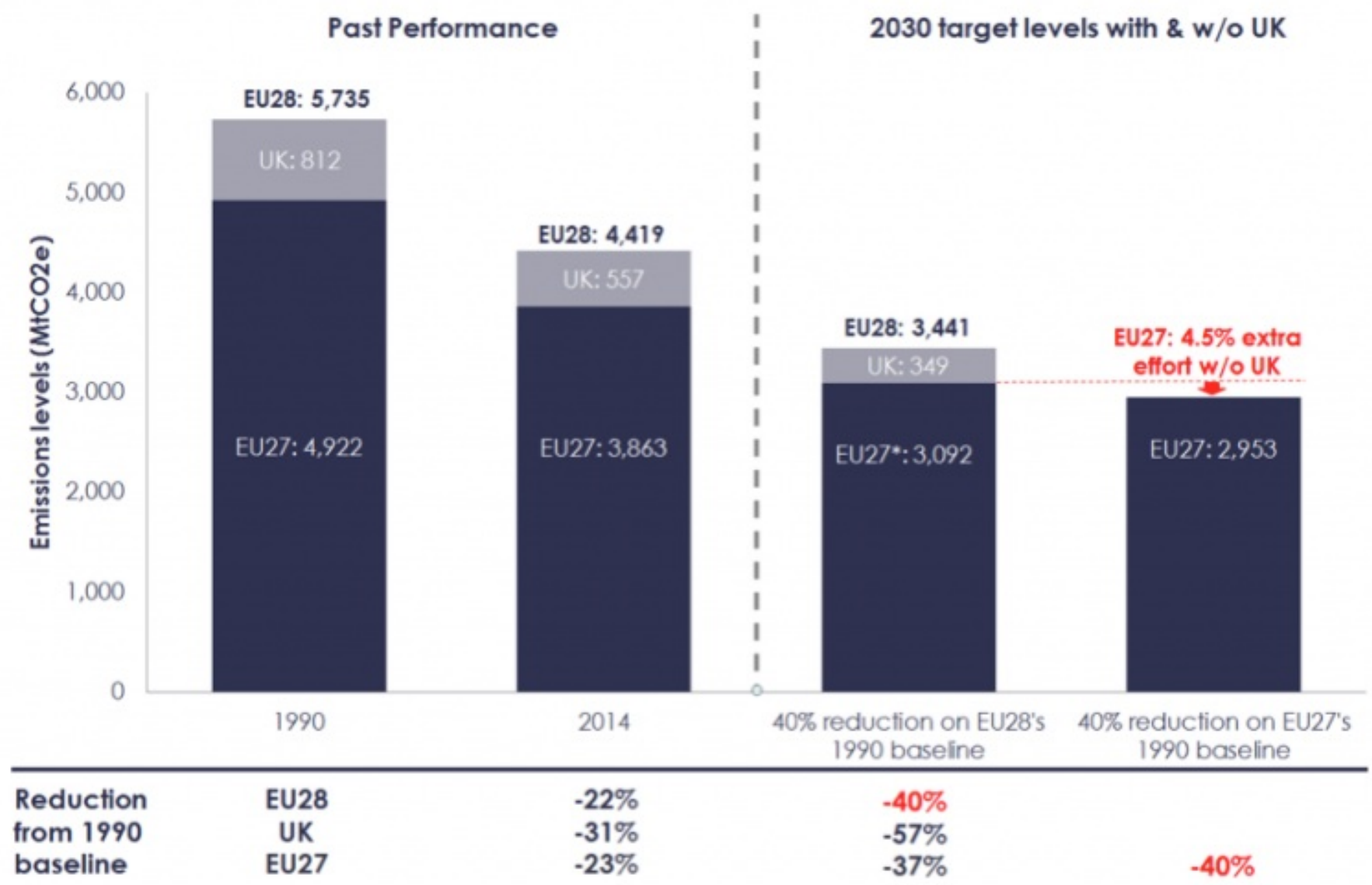

Source: Authors' calculations on 2030 target emissions levels for the EU28, EU27 and UK is based on 1990 emissions data from the EEA (2016).

Note: The amount of emissions the EU is allowed to produce in 2030 depends on whether the UK is part of the EU (EU28) or not (EU27). With the UK, the EU28 need to reduce their emissions by 40\% on EU28's 1990 levels by 2030. Once the UK's commitment (a 57\% reduction on UK 1990 levels) is subtracted from the EU28 total, the rest of the EU countries (EU27*) can produce 3,092MtCO2e in 2030. The emissions target in the EU27 after Brexit is the same 40\% reduction, but now measured relative to the EU27's 1990 baseline (reducing EU27 emissions to 2,953MtCO2e). The EU27 emissions in 2030 are about 138MtCO2e lower than under the pre-Brexit scenario of the EU27*. 
The re-distribution of the UK share can occur through two avenues. The EU can either reduce the emissions from the EU's Emissions Trading Scheme (EU ETS), which allows over 11,000 installations (accounting for about $45 \%$ of the EU's emissions from the power and emissions-intensive industries) to trade emissions permits. Additionally, the EU can further reduce emissions in the non-traded sector (buildings, transport and land-use), which are regulated through the Effort Sharing Directive.

The EU ETS is already undergoing reform to reduce an estimated surplus of 4.5 billion emissions permits (in December 2016 European lawmakers agreed to eliminate 1 billion of this surplus in 2021 ). Given this ongoing process it seems very likely that the additional reductions needed post-Brexit could be met through further reform to the EU ETS.

Meeting the shortfall in the non-traded sector is also feasible but would require additional policies. Analysis by the European Environmental Agency, Climate Action Tracker and the International Energy Agency all demonstrate that current policies in the EU are insufficient to meet even the existing targets. The EU would have to increase its efforts substantially, including in areas such as residential energy efficiency, transport (both surface and air) and land-use.

There is potential to reduce emissions further and compensate for the impact of Brexit, both in the EU ETS and in the non-traded sector. The more interesting question is how the EU27, without one of its leading climate change advocates, will go about meeting that challenge.

This post is part of the LSE-Statkraft Policy Research Programme: "Fit-for-Purpose' Energy and Climate Change Mitigation Policies for the European Union", and it represents the views of the author and not those of the Brexit blog, nor the LSE, nor Statkraft. Image: CCO Public Domain

Maria Carvalho is a policy analyst at the Grantham Research Institute on Climate Change and the Environment at the London School of Economics and Political Science.

Sam Fankhauser is co-director at the Grantham Research Institute on Climate Change and the Environment at the London School of Economics and Political Science.

- Copyright (C) 2015 London School of Economics 